\title{
Commentary: Optimal systemic arterial blood pressure after cardiac surgery
}

\author{
Juan A. Crestanello, MD
}

\author{
From the Department of Cardiovascular Surgery, Mayo Clinic, Rochester, Minn. \\ Disclosures: Author has nothing to disclose with regard to commercial support. \\ Received for publication Jan 15, 2019; accepted for publication Jan 16, 2019; available ahead of print Feb 14, \\ 2019. \\ Address for reprints: Juan A. Crestanello, MD, Department of Cardiovascular Surgery, Mayo Clinic, 200 First St \\ SW, Rochester, MN 55905 (E-mail: crestanello.juan@mayo.edu). \\ J Thorac Cardiovasc Surg 2019;158:1380-1 \\ $0022-5223 / \$ 36.00$ \\ Copyright (c) 2019 by The American Association for Thoracic Surgery \\ https://doi.org/10.1016/j.jtcvs.2019.01.048
}

What is the optimal systemic arterial blood pressure after cardiac surgery? Is it safe to target a higher systemic blood pressure after cardiac surgery, with the goal of improving renal and cerebral perfusion? Does higher systemic arterial blood pressure result in increased rates of bleeding or of other adverse or favorable outcomes? The answer to these questions is complex. Systemic arterial blood pressure is one of the many parameters that we use to monitor a patient's hemodynamics after cardiac surgery. Hemodynamic goals after cardiac surgery indicate that preload, afterload, blood pressure, and cardiac output should be optimized to maintain adequate organ perfusion and oxygen delivery, thus minimizing postoperative complications. 3,4 The evidence to support the blood pressure targets commonly used after cardiac surgery, however, is sparse. In addition, the ideal postoperative blood pressure and its impact on outcomes has not been determined. ${ }^{1,2}$ In theory, elderly patients or patients with preexisting hypertension, cerebrovascular disease, or kidney disease might benefit from a higher systemic postoperative blood pressure. Meanwhile, patients with left ventricular dysfunction, friable tissues, bleeding, or tenuous surgical repairs might benefit from lower blood pressure targets. The reports of either approach are empirical and not sustained by evidence. ${ }^{1-4}$ Although higher perfusion pressures during cardiopulmonary bypass are associated with lower rates of postoperative kidney dysfunction and stroke, ${ }^{5-7}$ postoperative hypertension has been associated with higher mortality, longer hospital stay, and higher incidence of renal dysfunction. ${ }^{8}$ Although there is concern that hypertension may cause or exacerbate postoperative bleeding, there is no evidence to support either this claim or the concept that permissive hypotension is protective of bleeding. ${ }^{\text {? }}$

In this issue of the Journal, McIlroy and colleagues ${ }^{10}$ report on the association of postoperative systemic arterial blood pressure and the bleeding markers of chest tube drainage and red blood cell transfusion after cardiac surgery. They found a negative association between arterial

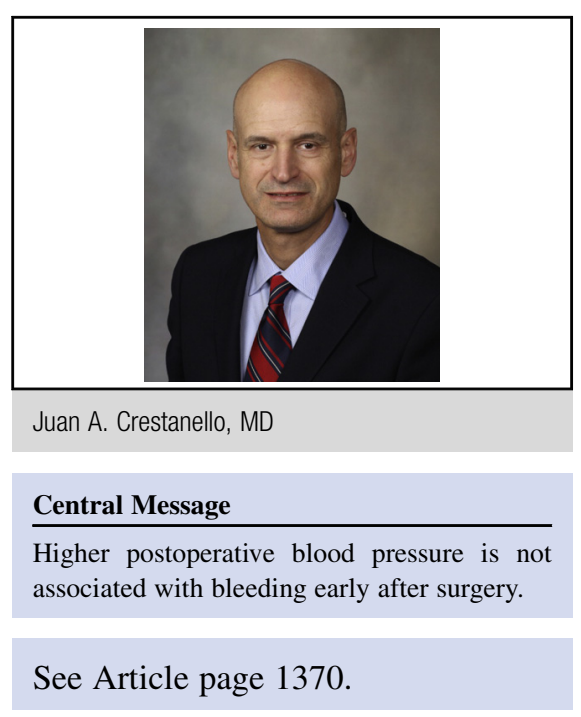

blood pressure and chest tube drainage and blood transfusion on the day of surgery. One might interpret this report as granting permission to allow higher blood pressures in the immediate postoperative period after cardiac surgery; however, the clinical significance of these findings should be interpreted within the limitations of the study. First, this was a secondary analysis of a prospective trial; as such, the study was not primarily designed to test the hypothesis of an association between blood pressure and bleeding. Second, bleeding (in the form of chest tube drainage) was only measure from intensive care unit admission to the end of the day of surgery. This fixed timeline reduced the observation period for patients with longer or more complex procedures who likely arrived at the intensive care unit later in the day. For example, a patient who underwent an 8-hour operation and arrived at the intensive care unit at 4 PM participated in the study for only 8 hours, whereas a patient who underwent a 4-hour operation participated for 12 hours. Late patients had a shorter window in which to have a drop in their hemoglobin level noted, to receive a blood transfusion, or to bleed enough for reexploration. Third, patients at high risk for bleeding were excluded from the analysis. Fourth, because McIlroy and colleagues ${ }^{10}$ only captured a single blood pressure reading for each patient, it is not possible to distinguish the effect of persistently elevated blood pressure from that of an isolated hypertensive peak on bleeding. Finally, this study did not associate elevated blood pressure with other 
significant clinical outcomes, such as renal failure or stroke. Despite these important limitations, however, this study offers the opportunity to reassess the way that we care for patients after cardiac surgery and highlights the need for better evidence to guide our daily practice.

\section{References}

1. Stephens RS, Whitman GJ. Postoperative critical care of the adult cardiac surgical patient. Part I: routine postoperative care. Crit Care Med. 2015;43:1477-97.

2. St André AC, DelRossi A. Hemodynamic management of patients in the first 24 hours after cardiac surgery. Crit Care Med. 2005;33:2082-93.

3. Osawa EA, Rhodes A, Landoni G, Galas FR, Fukushima JT, Park CH, et al. Effect of perioperative goal-directed hemodynamic resuscitation therapy on outcomes following cardiac surgery: a randomized clinical trial and systematic review. Crit Care Med. 2016;44:724-33.

4. Giglio M, Dalfino L, Puntillo F, Rubino G, Marucci M, Brienza N. Haemodynamic goal-directed therapy in cardiac and vascular surgery. A systematic review and meta-analysis. Interact Cardiovasc Thorac Surg. 2012;15:878-87.
5. Sun LY, Chung AM, Farkouh ME, van Diepen S, Weinberger J, Bourke M, et al Defining an intraoperative hypotension threshold in association with stroke in cardiac surgery. Anesthesiology. 2018;129:440-7. Erratum in: Anesthesiology. 2019;130:360.

6. Rettig TC, Peelen LM, Geuzebroek GS, van Klei WA, Boer C, van der Veer JW, et al. Impact of intraoperative hypotension during cardiopulmonary bypass on acute kidney injury after coronary artery bypass grafting. J Cardiothorac Vasc Anesth. 2017;31:522-8.

7. Brochard L, Abroug F, Brenner M, Broccard AF, Danner RL, Ferrer M, et al; ATS/ERS/ESICM/SCCM/SRLF Ad Hoc Committee on Acute Renal Failure. An official ATS/ERS/ESICM/SCCM/SRLF statement: prevention and management of acute renal failure in the ICU patient: an international consensus conference in intensive care medicine. Am J Respir Crit Care Med. 2010;181:1128-55.

8. Balzer F, Aronson S, Campagna JA, Ding L, Treskatsch S, Spies C, et al. High postoperative blood pressure after cardiac surgery is associated with acute kidney injury and death. J Cardiothorac Vasc Anesth. 2016;30:1562-70.

9. Nevin DG, Brohi K. Permissive hypotension for active haemorrhage in trauma. Anaesthesia. 2017;72:1443-8.

10. McIlroy D, Murphy D, Kasza J, Bhatia D, Marasco S. Association of postoperative blood pressure and bleeding after cardiac surgery. J Thorac Cardiovasc Surg. 2019;158:1370-9.e6. 